\title{
NOTE
}

\section{The Levels of Vasopressin in Cerebrospinal Fluid of Patients with Alcoholism}

\author{
T. NOTO*, N. KATO*, K. INOUE*, M. KITABAYASHI*, \\ AND T. NAKAJIMA** \\ *Department of Psychiatry, Kyoto Prefectural \\ University of Medicine, Kyoto, Japan \\ **Department of Neuropsychiatry, Osaka Daini-Keisatsu \\ Hospital, Ibaragi, Osaka
}

\begin{abstract}
Concentrations of arginine-vasopressin (AVP) in the cerebrospinal fluid (CSF) of 5 alcoholic patients and 6 healthy volunteers were determined by a radioimmunoassay.

The concentrations of AVP in the CSF of alcoholic patients were $2.93-6.17 \mathrm{pg} / \mathrm{ml}$ (the mean value, $4.80 \pm 1.34 \mathrm{pg} / \mathrm{ml}$ ) and those of healthy volunteers $3.80-12.59 \mathrm{pg} / \mathrm{ml}$ (the mean value, $9.87 \pm 3.19 \mathrm{pg} / \mathrm{ml}$ ). The AVP level in the CSF of alcoholics was significantly lower than that of normals $(\mathrm{P}<0.02)$.
\end{abstract}

Arginine-vasopressin (AVP) synthesized in the magnocells of supraoptic and paraventricular nuclei of mammals is transported to the target sites in the central nervous system (Buijs et al., 1978) and is supposed to play there some important roles, i.e. in memory mechanism (Van Wimersma Greidanus et al., 1975; De Wied, 1965; Ader and De Wied, 1972; King and De Wied, 1974; De Wied, 1971), biorhythmic mechanism (Zimmerman and Robison, 1976; Stetson and WatsonWhitmyre, 1976; Rusak and Zucker, 1975; Baltzer and Weiskrantz, 1975) etc. The neurosecretory fibers from the magnocells were shown to reach the wall of the lateral ventricle and the third ventricle (Buijs et al., 1978; Zimmerman, 1976). Therefore, AVP may be released directly into the cerebrospinal fluid (CSF). AVP in the CSF was thought to be involved in the control mechanism of intracranial pressure by regulating the water bal-

Received September 25, 1981. ance in CSF (Noto et al., 1978; Noto et al., (1979).

The CSF is also supposed to transport neurohormones to the target site in the brain (Van Wimersma Greidanus et al., 1975). On the basis of these experimental findings, AVP was clinically applied to the treatment of patients with memory disturbances.

Oliveros et al. (Oliveros et al., 1978) reported that the hormone was effective in alleviating some memory disturbances resulting from alcoholism and head injury and we also applied it intrathecally to the patients with dementia and obtained some favorable results (Nakajima et al., 1980). Recently it was also suggested to be that AVP is very effective in treating depression (Gold et al., 1978).

However, there was no direct evidence that patients with memory disturbances and depression had a lower level of AVP in the brain and even in the CSF because of difficulty in the microdetermination of the hormone. Alcoholism shows withdrawal symptoms, neu- 
rological signs, memory disturbances, a depressive mood and so on. AVP is effective in memory disturbances, depressive mood etc., so research on AVP levels in the central nervous system of alcoholics may be important in the therapy of alcoholism.

This paper reports the determination of AVP in the CSF and also data on the AVP level in the CSF of patients with alcoholism.

\section{Materials and Methods}

\section{The profiles of alcoholic patients}

Patient 1: A 32 year old man was admitted with muscle weakness, loss of emotional control and memory disturbances, and diagnosed as having alcoholism. He had drunk about $500 \mathrm{ml}$ of whisky daily and exhibited the above symptoms for several months before admission. He always began drinking in the morning.

Patient 2: A 65 year old man was admitted with convulsions and confusion, and diagnosed as having an acute alcohol withdrawal syndrome. He had drunk about 1 liter of "Shochu" (distilled spirits with about $40 \%$ alcohol content) a day. He had started drinking about 20 years ago.

Patient 3: A 54 year old man was admitted with tremors of the fingers and hands, hallucinations and convulsions, and diagnosed as having delirium tremens. He had drunk about $500 \mathrm{ml}$ of whisky daily for the past 7 years. He had started drinking 35 years ago.

Patient 4: A 55 year old man was admitted with sensory disturbances of the legs, sever insomnia, a delirious state and had attempted suicide, and was diagnosed as having delirium tremens. He had been drinking about $900 \mathrm{ml}$ of "Sake" (about $15 \%$ alcohol content) a day. He started drinking about 37 years ago.

Patient 5: A 75 year old man was admitted with insomnia, loss of appetite, disturbances in his gait and memory disturbances, and was diagnosed as an alcoholic. He had started drinking about 57 years ago and had been drinking $600-900 \mathrm{ml} /$ day of "Sake" for the previous 9 months.

\section{Collection of CSF samples}

CSF samples from the 5 alcoholic patients and 6 healthy volunteers who had normal liver function were collected by lumbar puncture at 9-10 am. $50 \mu 1$ of acetic acid was added to $5 \mathrm{ml}$ of the collected CSF and the acidified samples were stored at $-80^{\circ} \mathrm{C}$ until analyzed. The procedure for CSF collection was not fully standardized, but no anesthesia was employed. All the CSF samples collected were clear and their total protein content was within normal limits. The cell counts of the CSF samples were also within the normal range.
Radioimmunoassay of AVP in the CSF

Antisera were raised in white Japanese rabbits by injection of synthetic AVP (Sigma, Grade VI, $100 \mathrm{IU} / \mathrm{ml}$ ) conjugated with bovine serum albumin (Sigma, crystallized) (Vance et al., 1968). AVP was iodinated by $\mathrm{Na}^{125}$ I using chloramine $\mathrm{T}$ and the iodinated AVP was purified on Sephadex G-25 (Pharmacia Fine Chemicals).

1-Deamino, 8-D-arginine-vasopressin (DD-AVP) and oxytocin (Sigma, Grade III) were used for checking cross-reaction.

AVP in the CSF was absorbed by florisil (Wako Co., 100-200 mesh) activated by heating overnight at $400^{\circ} \mathrm{C}$. The CSF sample $(2.5 \mathrm{ml})$ was taken into a siliconized tube and $50 \mathrm{mg}$ of the activated florisil was added to it. Absorption of AVP was carried out under shaking at $4^{\circ} \mathrm{C}$ for $30 \mathrm{~min}$ (Beardwell, 1971) and the mixture was then centrifuged at $3,000 \mathrm{rpm}$ for $10 \mathrm{~min}$. The supernatant solution was aspirated off. The precipitate was washed twice with $1.5 \mathrm{ml}$ of distilled water and then twice with $1.25 \mathrm{ml}$ of $0.1 \mathrm{~N} \mathrm{HCl}$. AVP was eluted from the absorbent by shaking it in $2 \mathrm{ml}$ of acetone-water-acetic acid $(50: 49: 1$, by vol.) for 30 min. The suspension was centrifuged and the eluate was pooled. This extraction was repeated twice. The combined eluates in a tube were evaporated to dryness by gently blowing a constant air stream into the tube at room temperature.

The dried residue was dissolved in $500 \mu \mathrm{l}$ of the assay buffer $(0.01 \mathrm{M}$ phosphate buffer, $\mathrm{pH} 7.2$, containing $0.15 \mathrm{M} \mathrm{NaCl}, 0.1 \% \mathrm{NaN}_{3}$ and $0.05 \%$ bovine serum albumin). $200 \mu \mathrm{l}$ of the solution was used for the radioimmunoassay of AVP and duplicate determinations were performed. $50 \mu 1$ of the anti-AVP serum (dilution of $1: 20,000$ ) was added to the solution and the reaction mixture was incubated at $4^{\circ} \mathrm{C}$. After incubation for $24 \mathrm{~h}$ the iodinated AVP ( $50 \mu \mathrm{l}$, $5,000 \mathrm{cpm}$ ) was added to the mixture and incubation was further continued for the following $48 \mathrm{~h}$. For separation of bound and free ${ }^{125}$ I-AVP $100 \mu \mathrm{l}$ of $1 \%$ bovine $\gamma$-globulin and $1 \mathrm{ml}$ of $25 \%$ polyethyleneglycol were added to the reaction mixture, and it was then centrifuged at $3,000 \mathrm{rpm}$ for $40 \mathrm{~min}$. The supernatant solution was discarded and radioactivity of the precipitate was counted with an automatic gamma counting system (Nuclear Chicago, Model 4227). For the recovery check, $0,12.5,25,50 \mathrm{pg}$ of AVP was added at the first step of the extraction of AVP to $2.5 \mathrm{ml}$ of the CSF that had little endogenous AVP destroyed by freezing and thawing many times and the AVP measurements of the samples and the above samples for the recovery check were done at the same time.

\section{Results}

\section{Accuracy of the assay of AVP in CSF}

A standard curve of AVP and cross-reaction curves of oxytocin and DD-AVP using 


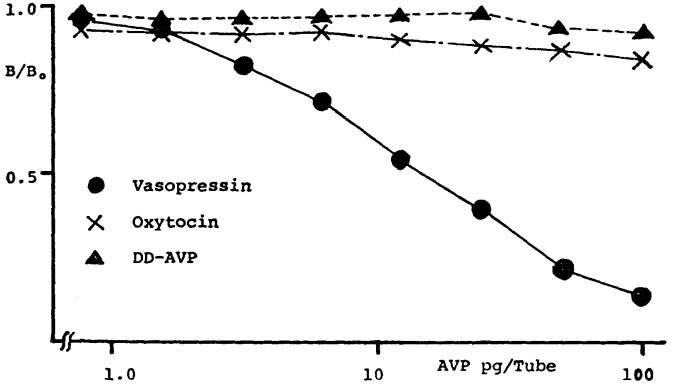

Fig. 1. A standard curve of AVP (-) and crossreaction curves of oxytocin $(x-x)$ and DDAVP ( $\Delta-\Delta)$ using the anti-AVP serum. $B_{0}$ represents the cpm of ${ }^{125}$ I-AVP bound to the anti-AVP serum under no cold AVP in the assay tube.

the anti-AVP serum are shown in Fig. 1. Oxytocin and DD-AVP were not combined with the anti-AVP serum under the conditions used. By this assay $1 \mathrm{pg}$ of $\mathrm{AVP} /$ tube was detectable. This means that over $1 \mathrm{pg}$ of AVP in $1 \mathrm{ml}$ of CSF is able to be determined. For the calculation of recovery of AVP in this assay CSF which had endogenous AVP almost destroyed by freezing and thawing was used. The recovery rate of AVP in this assay was $65.56 \pm 2.55 \% \quad(\mathrm{M} \pm \mathrm{SD}, \mathrm{n}=30)$. There was little difference among the recovery rates of the 3 concentrations of AVP.

\section{AVP content in $C S F$}

Table 1 shows the AVP levels in the CSF of 6 healthy volunteres and 5 alcoholic patients. The concentrations of AVP in the CSF of 6 volunteers were $3.80-12.59 \mathrm{pg} / \mathrm{ml}$ (the mean value, $9.87 \pm 3.19 \mathrm{pg} / \mathrm{ml}$ ) and those of 5 alcoholic patients $3.92-6.17 \mathrm{pg} / \mathrm{ml}$ (the mean value, $4.80 \pm 1.34 \mathrm{pg} / \mathrm{ml}$ ). The level of AVP in the CSF of the alcoholics is significantly lower than that of the controls $(\mathrm{P}<0.02)$.

\section{Discussion}

The AVP level in the CSF of 6 volunteers in the present study is very close to that reported by Dogterom et al. (Dogterom et al., 1978), but it is higher value than Jenkins, et al. (Jenkins, et al., 1980) and Luerssen, et al. (Luerssen, et al., 1977). The reason for the difference is not clear, but the amount of AVP in the material is known to decrease quickly under such unsuitable conditions as an unsuitable container, $\mathrm{pH}$, temperature and so on. Cross-reactivities of oxytocin and DD-AVP in the assay using the anti-AVP serum were very low, indicating the values obtained in this assay to be more reliable.

The lower level of AVP in the CSF of patients with alcoholism was first demostrated in this paper. Whether alcohol acts directly on the brain to lower the AVP level in the CSF or indirectly is a matter for further research. However, it is likely that alcohol may suppress the synthesis of AVP in the supraoptic and paraventricular nuclei or/and the release of AVP into the CSF because the intake of alcohol lowers the AVP level in serum (Noto et al., 1980). Since AVP is thought to play an important role in the

Table 1. AVP levels in the CSF of the alcoholic patients and health volunteers.

\begin{tabular}{cccc}
\hline Controls & AVP $(\mathrm{pg} / \mathrm{ml})$ & Patients & AVP $(\mathrm{pg} / \mathrm{ml})$ \\
\hline 1 & 12.59 & 1 & 3.43 \\
2 & 3.80 & 2 & 5.61 \\
3 & 12.59 & 3 & 6.17 \\
4 & 11.56 & 4 & 2.93 \\
5 & 7.61 & 5 & 5.84 \\
6 & 10.96 & & $4.80 \pm 1.34^{*}$ \\
\hline
\end{tabular}

$* \mathrm{P}<0.02$ alcoholics versus controls 
function of the brain, the suppression of AVP level in the CSF may cause or be the result of some neuropsychiatric symptoms of alcoholism. Whichever is true, increasing the level of AVP in the CSF may be helpful in treating alcoholism and the intrathecal injection of AVP may be used in the therapy of alcoholism.

\section{Acknowledgement}

This work was supported in part by Grant No. 577470 for Japanese Science Research from the Ministry of Education.

\section{References}

Ader, R. and de Wied, D. (1972). Effects of vasopressin on active and passive avoidance learning. Psychon. Sci. 29, 46-48.

Baltzer, V. and Weiskrantz, L. (1975). Antidepressant agents and reversal of diurnal activity cycles in the rat. Biol. Psychiatry. 10, 199-209.

Beardwell, C. G. (1971). Radioimmunoassay of arginine vasopressin in human plasma. J. Clin. Endocrinol. 33, 254-260.

Buijs, R. M., Swaab, D. F., Dogterom, J. and Van Leeuwen, F. W. (1978). Intra- and extra-hypothalamic vasopressin and oxytocin pathways in the rat. Cell. Tiss. Res. 186, 423-422.

Dogterom, J. M, Van Wimersma Greidanus, Tj. B. and de Wied, D. (1978). Vasopressin in cerebrospinal fluid and plasma of man, dog and rat. Am. J. Physiol. 234, 463-467.

Gold, P. W. and Goodwin, F. K. (1978). Vasopressin in Affective Illness. Lancet I, 1233-1236.

King, A. R. and de Wied, D. (1974). Localized behavioral effects of vasopressin on maintenance of an active avoidance response in rat. J. Comp. Physiol. Psychol. 86, 1008-1018.

Jenkins, J. S., Mather, H. M., and Ang V. (1980). Vasopressin in human cerebrospinal fluid. J. Clin. Endocrinol. Metab. 50, 364-367.

Luerssen, T. G., Shelton, R. L., and Robertson, G. L.
(1977). Evidence for separate origin of plasma and cerebrospinal fluid vasopressin. Clin. Res. 25, $14 \mathrm{~A}$.

Nakajima, T., Noto, T. and Inaoka, H. (1980). Vasopressin and brain functions. Jpn. J. Clin. Med. 38, 2237-2243. (in Japanese).

Noto, T., Nakajima, T. Saji, Y. and Nagawa, Y. (1978). Effect of vasopressin on intracranial pressure in rabbit. Endocrinol. Japan. 25, 591-596.

Noto, T., Nakajima, T., Saji, Y. and Nagawa, Y. (1979). Effect of vasopressin and cyclic AMP on water transport in arachnoid villi of cats. Endocrinol. Japon. 26, 181-186.

Noto, T., Inoue, K., Kitabayashi, M., Fukui, Y., Tanaka, K., Mori, M., Koh, M., Tadai, T., Katoh, $\mathrm{N}$, and Nakajima, T. (1980). Effect of alcohol intake on the serum AVP levels. Bull. Jpn. Neurochem. 19, 242-245. (in Japanese).

Oliveros, J. C., Jadali, M. K., Timsit-Berthier, M., Remy, R. and Moeglem, J. M. (1978). Vasopressin in amnesia. Lancet 1, 42-43.

Rusak, B. and Zucker, I. (1975). Biological rhythms and animal behavior. Ann. Rev. Psychol. 26, 137171.

Stetson, M. H. and Watson-Whitmyre, M. (1976). Nucleus suprachiasmaticus: The biological clock in the hamster? Science 191, 197-199.

Vance, V. K., Schure, J. J. and Reichlin, M. (1968). Induction of antibodies to porcine ACTH in rabbits with nonsteroidogenic polymers of BSA and ACTH. Proc. Soc. Expt. Biol. Med. 128, 347-350.

De Wied, D. (1965). The influence of the posterior and intermediate lobe of the pituitary and pituitary peptides on the maintenance of a conditioned avoidance response in rat. Int. J. Neuropharmacol. 4, 157-167.

De Wied, D. (1971). Long term effect of vasopressin on the maintenance of a conditioned avoidance response in rat. Nature 232, 58-60.

Van Wimersma Greidanus, Tj. B., Dogterom, J. and de Wied, D. (1975). Intraventricular administration of anti-vasopressin serum inhibits memory consolidation in rat. Life Sci. 16, 637-644.

Zimmerman, E. A. (1976). Localization of hypothalamic hormones by immunocytochemical techniques. Front. Neuroendocrinol. 4, 25-62.

Zimmerman, E. A. and Robinson, A. G. (1976). Hypothalamic neurons secreting vasopressin and neurophysin. Kidney Int. 10, 12-24. 